\title{
Fluoride: A topical discussion
}

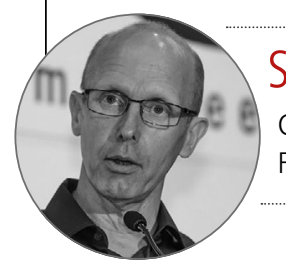

Simon Hearnshaw

Coordinator, Community Water Fluoridation (CWF) Network

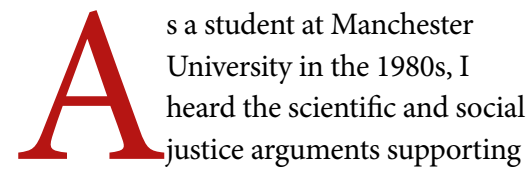
community water fluoridation (CWF).

Professor Mike Lennon, chair of the British Fluoridation Society (BFS), was my lecturer, yet the arguments went completely over my head. Fast forward 25 years and as a practice owner in central Hull, one of the most socially disadvantaged areas in England, I saw things differently. The city topped the league in depressing tables: the most deprived, highest youth unemployment, most teenage pregnancies, and the worst oral health.

There was one thing I believed we could improve and that was oral health, particularly that of children giving them what the Marmot Review describes as the best start in life. As a member of the Local Dental Committee, we set out to make a difference. Teeth Team was born in Hull led by Chris Groombridge and Ingrid Perry and we started the CWF campaign for Hull before eventually going national as the CWF Network.

So where are we now? David Westgarth's article nicely summarises the position. ${ }^{1}$ I think support for CWF is slowly growing within the profession as colleagues switch on to the powerful influence we have across our patients and local communities. I'm seeing this more and more now, and this is a testament to the whole dental team's commitment to drive positive change which is immensely impressive. Having the National Children's Bureau as a Network partner is powerful because it takes the lobby outside dentistry. Certainly, in the early days of the campaign around 2012, there was a sense of nervousness around mentioning the F-word. At the time CWF was being buried in the 'basket of measures' at perhaps third or fourth place. I think now we understand that the basket is the right approach, as Claire says, except in areas like Hull, CWF is number one. Of course, we need a multi-faceted approach ${ }^{2}$ using all the evidence base including, better prevention within the dental contract, outreach programmes like school based supervised brushing and fluoride varnish programmes and better evidence-based behaviour change approaches, but in areas of high needs we need more. This is where the argument for CWF is easiest to make.

Rebecca Linney's suggestion that social media is important mainly because these are the platforms with the potential to reach the greatest number of people is key. The website we created to support water fluoridation in Hull $^{3}$ places simple evidence-based messages helping to drive health improvement understanding and to myth bust where necessary. It's a powerful educational tool.

I agree with Barry Cockcroft that the anti-fluoride lobby is quite small but loud. Recently there has been a much bigger pro-F lobby on social media including the American Fluoridation Society, the British Fluoridation Society, the CWF Network and a growing group of organisations like Making Sense of Fluoride and Campaign Dental Health.

It's very important to stress that this isn't an ideological campaign, but an evidence-based campaign, and the wider lobby looks at all research both positive and negative through the lens of critical science. Overwhelmingly, science tells us CWF is safe, effective, and cost effective as Claire Stevens emphasises. ${ }^{4}$ Clinically, as both Nigel and Barry observe, the differences between the oral health in fluoridated and nonfluoridated areas is obvious and the clinical data reinforces this emphatically.

So, what next? I think we need to push on, and as Nigel and Claire say, get better organised at national and local levels. Nationally, we need to continue building the Network. It is great to have the support of the National Children's Bureau and Amanda Allard's perspective that the public may not be aware of the impact of poor oral health on general health and quality of life is something we need to work hard to change.

Locally we need to be ready to support Councils moving towards public consultation. I absolutely agree with Amanda, Claire, and Barry that the proposals in the white paper have the potential to remove barriers to implementation, but I also agree with Nigel that professional and network support for CWF is critical. In the areas where CWF schemes may be proposed, whole dental team support, reinforcing the positive messages, answering questions, using resources will make a difference. 5

Professor Sir Michael Marmot, the international champion of health equality, says that there are things we can do to drive positive change and reduce inequalities in oral health. And I agree. Is it acceptable that health is linked to deprivation? Of course not. Introducing a water fluoridation scheme (described as one of ten greatest public health achievements of the $20^{\text {th }}$ century ${ }^{6}$ in an area like Hull with poor oral health allows us to contribute to reversing this.

If we follow the science and introduce fluoride at a miniscule percentage costing around $£ 1$ per person per year this will irrefutably improve oral health and perhaps play a small part in tipping the balance. I think reducing health inequality is the most cogent argument to use within the CWF debate and I am certain that as a profession we can make this, using the evidence base, bringing fluoridation closer to becoming a reality. The last scheme to be implemented was in the year that I qualified in 1984. It's possible that my career may start and finish with successful fluoridation improving health safely, effectively and reducing inequality. •

\section{References}

1. Westgarth $D$. Turning the taps on: Is water fluoridation closer to becoming a reality? BDJ In Pract 2021; 34: 14-19.

2. Public Health England. Local authorities improving oral health: commissioning better oral health for children and young people. An evidence-informed toolkit for local authorities. June 2014. Available online at: https://assets.publishing.service.gov.uk/ government/uploads/system/uploads/attachment data/file/321503/CBOHMaindocumentJUNE2014. pdf (Accessed June 2021)

3. One Part Per Million. Available online at: https:// onepartpermillion.co.uk/ (Accessed June 2021).

4. Public Health England. Return on investment of oral health improvement programmes for 0-5 year olds. 2016. Available online at: https://assets.publishing service.gov.uk/government/uploads/system/ uploads/attachment_data/file/560973/ROI_oral health_interventions.pdf (Accessed June 2021).

5. Public Health England. Public library: Water fluoridation resources. Available online at: https://khub.net/web/phe-national/public-library/-/document_library/v2WsRK3ZIEig/ view/210540449 (Accessed June 2021).

6. CDC.gov. Community Water Fluoridation. Available online at: https:// www.cdc.gov/fluoridation/pdf/ communitywaterfluoridationfactsheet.pdf (Accessed June 2021).

https://doi.org/10.1038/s41404-021-0811-7 